\title{
Methodology for assessment of technogenic contamination in water bodies at urban areas
}

\author{
Valentina Kurochkina ${ }^{1 *}$ \\ ${ }^{1}$ Moscow State University of Civil Engineering, Yaroslavskoye Shosse, 26, Moscow, 129337, Russia
}

\begin{abstract}
The paper considers the problem of the influence of man-made load on the quality of water and bottom sediments of water bodies. The relationship of the state of the water body, the quality of the water in it and the level of contamination of bottom sediments is established. It has been shown that the rates and volumes of formation of bottom sediments and the level of contamination of their layers are different throughout the existence of a water body, which allows the use of bottom sediments as the main indicator of the ecological state of a water body, reflecting the level of anthropogenic impact on water ecosystems over time.
\end{abstract}

\section{Introduction}

The processes of urbanization of the territory of the Russian Federation lead to an increasing effect of technogenic factors on water bodies, especially in cases where water bodies are located directly in the centers of urbanization or in the zones of their influence. The rates of the negative impact of urbanization on water bodies increase as the urban population, industry and water transport grow [1-3]. A significant proportion of the river flow is withdrawn for water supply of economic activity in cities, large volumes of untreated or conditionally clean wastewater are discharged into the rivers, which leads to a change in the hydrological regime and the course of intra-river processes. This also leads to the accumulation of a significant amount of contaminated bottom sediments in the river channels, which adversely affect the quality of water and the general ecological condition of water streams.

Since the negative impact of urbanization on water bodies with varying degrees of intensity lasts more than 100 years, the volume of contaminated sediments accumulated in river channels reaches critical values. In some cases, channel sediments cannot be removed by the river flow on its own, which necessitates the implementation of measures to clean the channels and develop measures for the disposal of removed contaminated sediments.

The rates and volumes of formation of bottom sediments and the level of contamination of their layers are different throughout the existence of a water body, which allows both tracking the effect of a changing man-made load on river ecosystems in time and the change in those natural processes that occur in it. Therefore, in a number of countries, bottom sediments are used as the main indicator of the ecological state of a water body, reflecting the level of technogenic impact on river ecosystems [4-6].

*Corresponding author: kurochkina@mgsu.ru 
The volume and significance of this problem can be illustrated by the following figures: in Russia, there are about 3 million lakes, about 1,000 large reservoirs, a total area of a water mirror of 11.9 million hectares, over 100 thousand artificial ponds, 3 million small rivers. A significant part of these water bodies was subjected to technogenic and anthropogenic impacts, silted up, contaminated, and requires cleaning.

When developing environmental measures aimed at solving the problems of sustainable development of urbanized territories, protecting the natural environment and creating favorable living conditions for the population, it is necessary to rely on the scientific criteria of environmental safety of natural and economic geosystems.

The need to develop environmental safety criteria for contaminated bottom sediments arises not only when assessing the ecological state of water systems as a whole, but also when solving various engineering measures, for example, related to changing the channel cross-sectional shape, while dredging or restoring natural parameters of the riverbed. The solution to these problems is directly related to the choice of technology for the removal and disposal of bottom sediments, which should be determined, on the one hand, by the volume and distribution of contaminated sediments in the channel, and on the other hand, by an assessment of their possible environmental impact [7].

\section{Materials and methods}

The generally accepted approach of normative methods for determining the level of environmental pollution by comparing the concentrations of certain pollutants with their maximum permissible concentrations (MPC) is not possible, since MPC of pollutants and clarks of bottom sediments have not yet been developed.

For a quantitative assessment of the degree of technogenic contamination of bottom sediments, Yu.E. Saet et al. proposed [8-12] an indicative scale for characterizing the level of technogenic contamination and the degree of potential sanitary and toxicological hazard of bottom sediments (Tab. 1).

Table 1. Indicative scale for assessing the contamination of water systems by the rate of accumulation of chemical deposits in bottom sediments.

\begin{tabular}{c|l|l}
\hline $\begin{array}{c}\text { Contamination factor } \\
\text { Zc }\end{array}$ & \multicolumn{1}{c}{$\begin{array}{c}\text { Level of technogenic } \\
\text { contamination }\end{array}$} & \multicolumn{1}{c}{$\begin{array}{c}\text { Degree of sanitary toxicological } \\
\text { hazard }\end{array}$} \\
\hline$<10$ & Weak & Permissible \\
\hline $10-30$ & Average & Moderate \\
\hline $30-100$ & High & Dangerous \\
\hline $100-300$ & Very high & Very dangerous \\
\hline$>300$ & Extremely high & Extremely dangerous \\
\hline
\end{tabular}

In this scale, the total contamination index $(\mathrm{Zc})$ and chemical concentration factors $(\mathrm{Kc})$ are used to assess the state of water systems. They are also based on local background concentrations of bottom sediment elements:

$$
\mathrm{Z}_{\mathrm{c}}=\Sigma \mathrm{Kc}-(\mathrm{n}-1)
$$

where $\mathrm{Kc}-$ the technogenic concentration coefficients are greater than 1 (or 1.5), $\mathrm{n}$ is the number of elements with $\mathrm{Kc}>1$ (or 1.5):

$$
\mathrm{Kc}=\mathrm{C} / \mathrm{C}_{\mathrm{b}}
$$


Figure 1 shows the concentration coefficients of chemicals in bottom sediments of the YauzaRiver, calculated for elements with known background values [13].

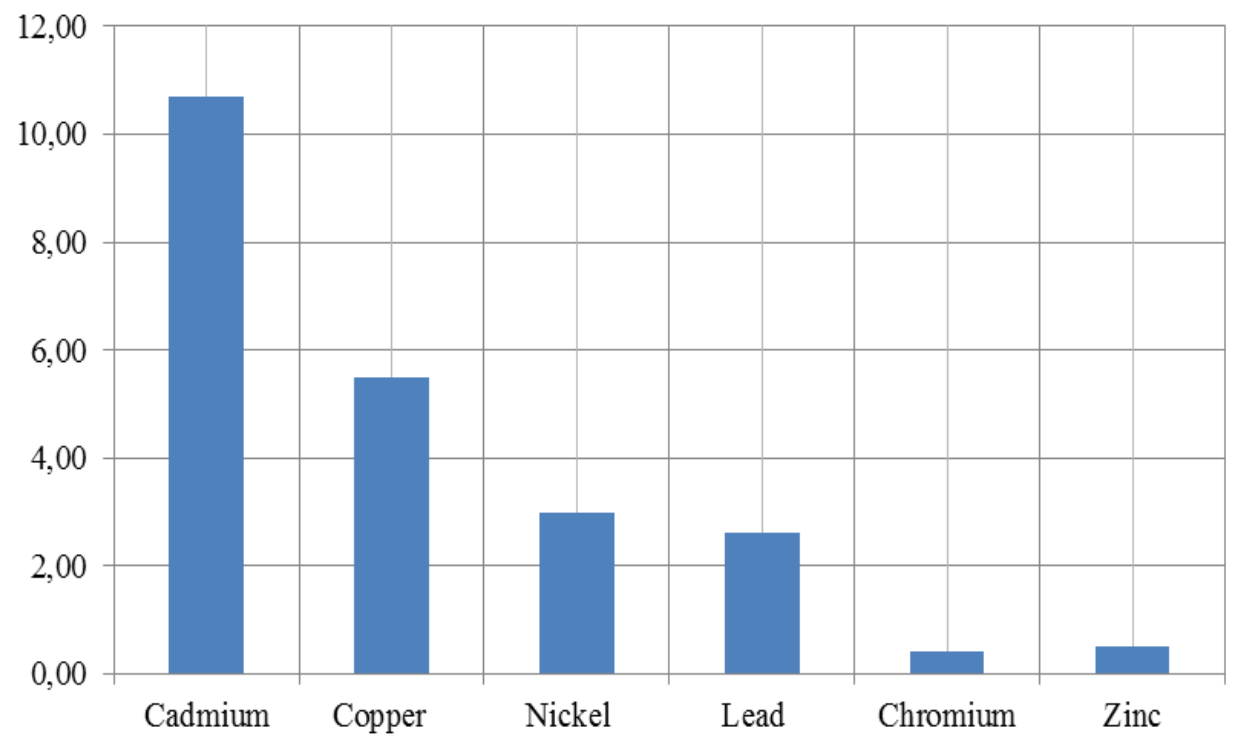

Fig. 1. Impurity concentration coefficient in bottom sediments

When studying the composition of bottom sediments, specificallycontamination by heavy metals, it is very important to take into account the differences in samples in terms of mechanical composition. HM in soils are concentrated mainly in clay sediments [14-19]. Various physicochemical processes, such as adsorption, osmosis, and ion exchange, proceed on the mineral - water interface. Their development depends on the dispersion of the solid component and significantly increases with an increase in the total specific surface.Therefore, they are most characteristic for clay and other finely dispersed minerals [20]. This is the basis for the widely used in Germany methodology for assessing the manmade load on river ecosystems: in order to correlate samples of different mechanical composition, the contamination of a fraction of less than $0.020 \mathrm{~mm}$ is used with clay particles prevailing in it. In this way, samples taken in various sections of the river are brought to a "common denominator", and technogenic contamination of the river is estimated by the degree of saturation of the clay fraction of bottom sediments with heavy metals.

Igeo-classes or "geo-accumulation indices" proposed by G. Muller, which are determined on the basis of the following equation, are used to determine the degree of contamination[21,22]:

$$
I_{\text {geo }}=\log _{2}\left(C / 1.5 C_{b}\right)
$$

where $\mathrm{C}-$ measured (gross) element concentration in bottom sediments (fractions of less than $0.02 \mathrm{~mm}$ are most often used as having the highest sorption capacity);

$\mathrm{Cb}$ - geochemical background concentration of the element $\mathrm{n}$, is determined according to specific studies considering regional specificities of the dissipation of the element $n$;

1.5 - coefficient taking into account variations in the natural concentrations of the element. 
This indicator is the basis for classifying bottom relations of water bodies by one of the quality classes (Table 2).

Table 2. Characterization of contamination levels of bottom sediments by Igeo-classes and man-made load on aquatic ecosystems

\begin{tabular}{|c|c|c|c|}
\hline Igeo-class & Contamination level & $\begin{array}{l}\text { Man-made load on } \\
\text { aquatic ecosystems }\end{array}$ & $\begin{array}{l}\text { Ecological zones of aquatic } \\
\text { ecosystems; bottom sediment } \\
\text { state classes }\end{array}$ \\
\hline $\begin{array}{c}\text { Background } \\
\text { values }\end{array}$ & Almostuncontaminated & $\begin{array}{c}\text { Minor } \\
\text { (non-hazardous) }\end{array}$ & Natural background state \\
\hline $0-1$ & $\begin{array}{c}\text { Almostuncontaminated } \\
\text { to moderately } \\
\text { contaminated } \\
\end{array}$ & $\begin{array}{c}\text { Weak } \\
\text { (low hazardous) }\end{array}$ & $\begin{array}{l}\text { Normal zone; class of } \\
\text { satisfactory condition }\end{array}$ \\
\hline $2-3$ & $\begin{array}{c}\text { Moderately } \\
\text { contaminated to } \\
\text { medium contaminated }\end{array}$ & $\begin{array}{l}\text { Moderate } \\
\text { (moderately } \\
\text { hazardous) }\end{array}$ & $\begin{array}{l}\text { Risk zone; class of adverse } \\
\text { condition }\end{array}$ \\
\hline $4-5$ & $\begin{array}{l}\text { Medium contaminated } \\
\text { to highly contaminated }\end{array}$ & $\begin{array}{c}\text { Strong } \\
\text { (hazardous) }\end{array}$ & $\begin{array}{c}\text { Crisis zone; class of very } \\
\text { adverse condition }\end{array}$ \\
\hline 6 & $\begin{array}{c}\text { Highly contaminated to } \\
\text { excessively } \\
\text { contaminated }\end{array}$ & $\begin{array}{c}\text { Excessive (extremely } \\
\text { hazardous) }\end{array}$ & $\begin{array}{l}\text { Disaster zone; class of } \\
\text { catastrophic condition }\end{array}$ \\
\hline
\end{tabular}

The assessment of the level of contamination of bottom sediments with heavy metals by Mueller form a simple system of geo-accumulation classes (Table 2), which allows mathematically determining the classification indicators for assessing the ecological state of bottom sediments and "localizing" the places of formation of bottom sediments with maximum concentrations of pollutants.

Figure 2 shows the values of the $I_{\text {geo }}$ geo-accumulation indices reflecting an estimate of the level of contamination of bottom sediments of German rivers with cadmium $(\mathrm{Cd})$. The background value of cadmium contamination $\mathrm{Cd}_{\mathrm{b}}=0.3 \mu \mathrm{g} / \mathrm{kg}$.

When assessing the level of contamination and environmental hazard of bottom sediments to be removed, processed and disposed, as a rule, approaches based on the use of background concentrations (or the values of maximum permissible concentrations of substances in water) are used. The complexity of the application of such methods lies in the fact that if in Europe sufficient attention is paid to the study of background values, then for Russia, these studies are locally selective. Therefore, clarks of the lithosphere, soils, etc. are often taken as background values. In this regard, it seems appropriate to use the hazard coefficient of chemical elements K0as an additional criterion [23]:

$$
\mathrm{Kc}=\mathrm{Ci} / \mathrm{MPCi}
$$

where, $\mathrm{Ci}$ - concentration of controlled substances in bottom sediments;

MPCi - the maximum permissible concentration of these substances in the soils corresponding to them [24.25]. 


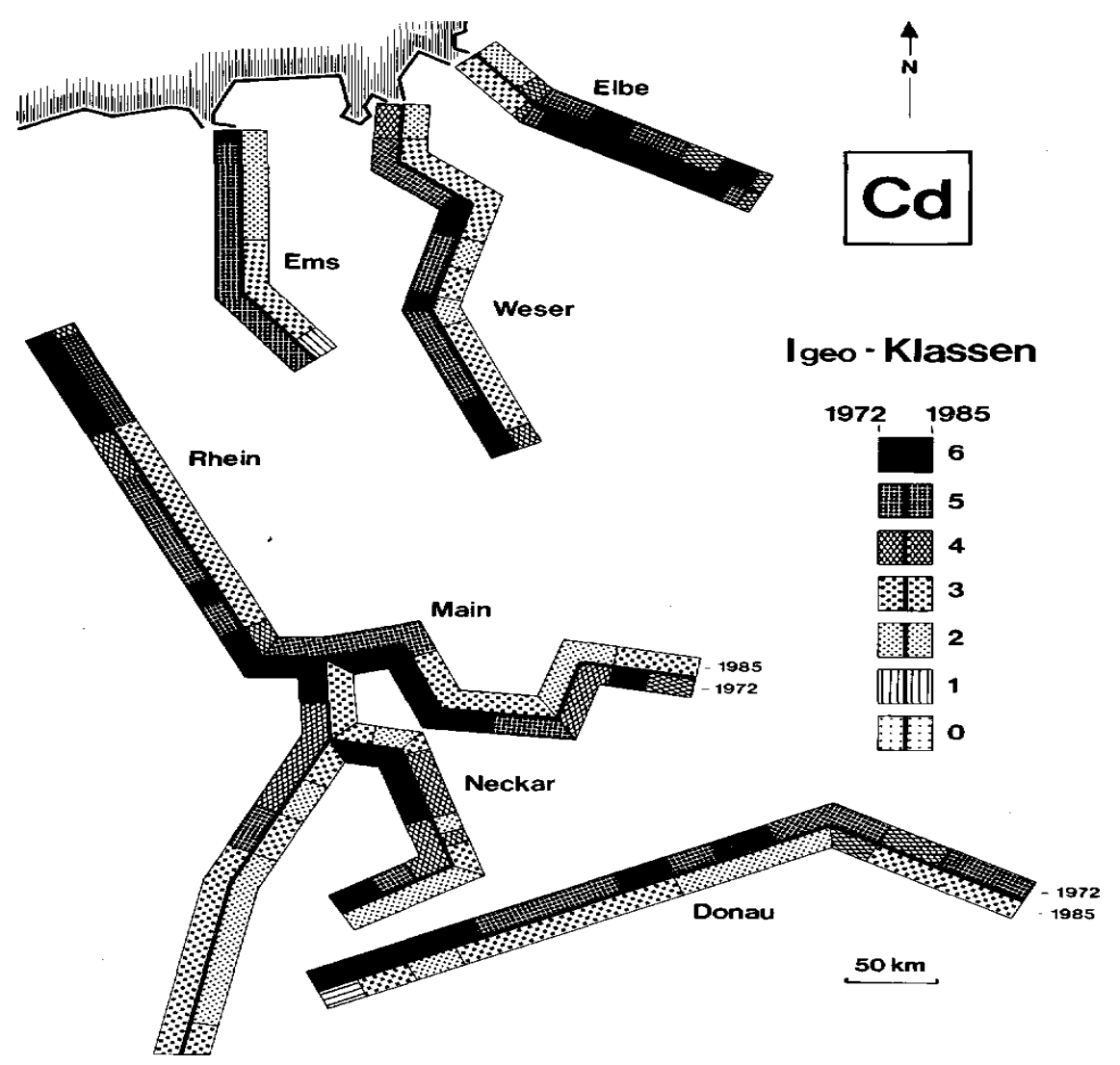

Fig. 2. Assessment of the level of contamination of bottom sediments of the most important German rivers with cadmium $(\mathrm{Cd})$ for 1972 and 1985 [22]

Table 3 shows the values of the hazard coefficient $\mathrm{K}_{0}$ calculated for the bottom sediments of the Yauza River.

Similarly to soils, the level of contamination of bottom sediments of a water body by each element in accordance with its hazard class is established.

Table 3. Hazard coefficientsof chemical elements $\left(\mathrm{K}_{0}\right)$

\begin{tabular}{|c|c|c|c|c|}
\hline \multirow{2}{*}{ Elements } & \multirow{2}{*}{$\begin{array}{l}\text { MPC/TPC of } \\
\text { elements in the } \\
\text { soil }\end{array}$} & \multicolumn{3}{|c|}{ Bottom sediments } \\
\hline & & Gross content & $\mathrm{K}_{0}$ & Hazard class \\
\hline Cadmium (Cd) & 0.5 & 3.04 & 6.08 & 1 \\
\hline Copepr $(\mathrm{Cu})$ & 33 & 160.5 & 4.86 & 2 \\
\hline Arsenic(As) & 2 & 5.19 & 2.6 & 1 \\
\hline Nickel (Ni) & 20 & 51.7 & 2.6 & 2 \\
\hline Mercury $(\mathrm{Hg})$ & 2.1 & 0.658 & 0.31 & 1 \\
\hline Lead $(\mathrm{Pb})$ & 32 & 74.7 & 2.33 & 1 \\
\hline Zinc $(\mathrm{Zn})$ & 55 & 57.3 & 1.04 & 1 \\
\hline
\end{tabular}


This allowed us to propose a scale for assessing the contamination of bottom sediments, which differentially takes into account the contribution of the studied chemical elements representing various environmental hazards (Tab. 4).

Table 4. Levels of contamination of bottom sediments with chemicals under the study

\begin{tabular}{|c|c|c|c|c|c|c|c|c|c|c|}
\hline \multirow{2}{*}{$\begin{array}{c}\text { Level of } \\
\text { contamination }\end{array}$} & \multicolumn{6}{|c|}{ Hazard class 1} & \multicolumn{3}{|c|}{ Hazard class 2} & \multirow{2}{*}{$\begin{array}{c}\begin{array}{c}\text { Hazard } \\
\text { class } 3\end{array} \\
\mathrm{~K}_{0}\end{array}$} \\
\hline & $\mathrm{K}_{0}$ & $\mathrm{Cd}$ & As & $\mathrm{Hg}$ & $\mathrm{Pb}$ & $\begin{array}{l}\mathrm{Z} \\
\mathrm{n}\end{array}$ & $\mathrm{K}_{0}$ & $\begin{array}{l}\mathrm{C} \\
\mathrm{u}\end{array}$ & $\mathrm{Ni}$ & \\
\hline $\begin{array}{c}\text { Excessively } \\
\text { contaminated }\end{array}$ & $>2.5$ & $X$ & & & & & $>4$ & & & $>5.5$ \\
\hline $\begin{array}{c}\text { Highly } \\
\text { contaminated }\end{array}$ & $\begin{array}{c}\text { from 2to } \\
2.5 \\
\end{array}$ & & $X$ & & X & & $\begin{array}{l}\text { from } \\
3 \text { to } 4\end{array}$ & $X$ & & $\begin{array}{c}\text { from } 4 \text { to } \\
5.5 \\
\end{array}$ \\
\hline $\begin{array}{c}\text { Medium } \\
\text { contamination }\end{array}$ & $\begin{array}{l}\text { from } 1.5 \\
\text { to } 2 \\
\end{array}$ & & & & & & $\begin{array}{l}\text { from } \\
2 \text { to } 3\end{array}$ & & $X$ & $\begin{array}{l}\text { from } 2.5 \\
\text { to } 4 \\
\end{array}$ \\
\hline $\begin{array}{c}\text { Low } \\
\text { contamination }\end{array}$ & $\begin{array}{c}\text { from 1to } \\
1.5 \\
\end{array}$ & & & & & $X$ & $\begin{array}{l}\text { from } \\
1 \text { to } 2\end{array}$ & & & $\begin{array}{c}\text { from } 1 \text { to } \\
2.5 \\
\end{array}$ \\
\hline $\begin{array}{c}\text { Moderately } \\
\text { contaminated }\end{array}$ & $\begin{array}{c}\text { less } \\
\text { than } 1\end{array}$ & & & $X$ & & & $\begin{array}{l}\text { less } \\
\text { than } 1\end{array}$ & & & $\begin{array}{c}\text { less than } \\
1\end{array}$ \\
\hline
\end{tabular}

\section{Conclusion}

In accordance with this methodology, the total hazard class of bottom sediments is determined by the highest value of the heavy metal content from those found in bottom sediments.

The proposed classification can be used to assess the man-made load on river ecosystems and identify ecologically unfavorable sections of rivers, which, according to the authors, will help in choosing effective technologies for the protection and purification of water bodies.

\section{References}

1. V.I. Telichenko, V.M. Roytman, A.A. Benuzh, Integrated safety in construction. NIU MGSU, (2015).

2. V.I. Telichenko, Industrial and civil engineering. 11, 50-54 (2008).

3. V.I. Telichenko, A.D. Potapov, M.Yu.Slesarev, E.V. Shcherbina, Environmental safety of construction Arkhitektura-S (2009).

4. T.G. Bogomolova, V.A. Kurochkina, Bulletin MGSU. 2, 4, 399-405 (2010).

5. V. A. Kurochkina, Natural and technical sciences. 9-10, 452-455 (2014).

6. J.B. Ellis, Water. Res. 80, 970, 730-734 (1976).

7. T.G., Bogomolova, V.A. Kurochkina, Engineering survey. 10, 56-60 (2010).

8. Yu.E. Saet, R.S. Smirnova, Geochemical printsipy of identification of zones of impact of industrial emissions in urban agglomeration. Landscape and geochemical mapping and environmental protection. Think (1983).

9. Yu.E. Saet, B.A. Revich, E.P. Yanin, Geochemistry of the environment (Bosom, 1990). V.V. Dobrovol'skiy, Soil science. 5, 639-645 (1999). 
10. E.P. Yanin, Technogenic river and industrial zones (formation, composition, geochemical features). IMGRE (2002).

11. E.P. Yanin, Theoretical and Applied Ecology. 1 (2009).

12. V.A. Kurochkina, Formation and environmental properties of riverbed deposits in watercourses in urban areas. Moscow State University of Civil Engineering (2012).

13. V.I. Kosov, G.N. Ivanov, V.V. Levinskiy, Bulletin TGTU. 1(1), 5-9 (2002).

14. G.Sh. Kuzhina, Dynamics of trace elements in water and bottom sediments of the upper rivers of the Southern Urals: Belaya and Ural Sibay (2010).

15. Dzh. Mur, S. Ramamurti, Heavy Metals in Natural Waters: Monitoring and Evaluation of Impact. Peace (1987).

16. P.N.Linnik, B.I. Nabivanets, Formation of migration of metals in fresh surface water Hydrometeo- publish, (1986).

17. D.P. Fokin, G.T. Frumin, A.E. Rybalko, Ecological chemistry. 19, 4, 236-242 (2010).

18. Dobrovolskiy V.V. Geografiya mikroelementov. Globalnoerasseyanie. M.: Mysl, (1983).

19. V.V. Kovalskiy, Geochemical ecology (Science, 1986).

20. N.V. Kolomiytsev, A.O. Shcherbakov, G. Myuller, Life of the earth. 30, 164-171 (1997).

21. G. Müller, Schadstoffe in Sedimenten-Sedimente als Schadstoffe. UmweltgeologieBand. 